\title{
ASPECTOS ANATÔMICOS DOS ÓRGÃOS VEGETATIVOS DE Passiflora alata Dryander (PASSIFLORACEAE).
}

\author{
Vera Lúcia Carvalho Siqueira, Thais Scotti do Canto-Dorow e Maria \\ Helena Lunardi
}

Departamento de Biologia - Centro de Ciências Naturais e Exatas

UFSM. Santa Maria, RS

RESUMO -

Este trabalho apresenta um estudo anatômico da raiz, caule e folha de Passiflora alata Dryander (Passifloraceae). Esta espécie é reconhecida no Rio Grande do Sul por seu valor medicinal, sendo indicada como calmante e diurética. O material analisado foi coletado no Campus da UFSM, Santa Maria, RS. O estudo foi realizado utilizando-se as técnicas usuais de histologia vegetal. O padrão anatômico da folha, em corte transversal, revela uma organização dorsiventral e hipostomática. Destaca-se ainda a ausência de tricomas; estômatos do tipo anomocítico; feixe vascular colateral. Em corte transversal, o caule de estrutura primária apresenta epiderme unisseriada, cuticula espessa, ausência total de tricomas, os feixes vasculares são colaterais. A raiz primária, em corte transversal é tetrarca, o parênquima cortical apresenta idioblastos, com conteúdo semelhante as células taniniferas presentes na endoderme

\section{SUMMARY -}

This paper deals with a anatomical study of the root, stem and leaf of Passiflora alata Dryander (Passifloraceae). This species is recognized in Rio Grande do Sul by its medicinal value, indicate as calmative and diuretic. The material analysed was collected in the Campus of UFSM, Santa Maria, RS. The study was realized using the usual technics of the vegetal histology. The anatomical pattern of the leaf, in cross-section, shows a dorsiventral and hypostomatic organization; absence of trichomes, anomocytic stomata; collateral bundle vascular. In cross-section, the young stem shows epidermis uniseriate; thick cuticle; total absence of trichomes; the bundles vascular are collateral. The primary root, in cross-section, is tetrach, the parenchyma cortical shows idioblastic cells, with tanniniferous contents. 


\section{INTRODUÇÃO}

Passiflora alata Dryander pertence à familia Passifloraceae, que compreende cerca de 12 gêneros e 400 espécies. Das 114 espécies atualmente referidas para o Brasil, 14 ocorrem no Rio Grande do Sul (SACCO, 1980).

Passiflora alata é originária do Peru e Brasil (Bahia à Santa Catarina), sendo muito cultivada no Rio Grande do Sul, onde é conhecida popularmente como maracujá-de-refresco. Neste Estado, o caule e folhas de $\underline{\mathbf{P}}$ alata são utilizadas na medicina popular como calmante e diurético. COIMBRA (1942) citou que suas folhas tem ação sedativa e hipnótica. Passiflora alata é também considerada uma importante espécie alimentar pelos seus frutos, cuja polpa, de agradável sabor, é especialmente útil para preparação de sucos, sorvetes e aperitivos (RIZZINI \& MORS, 1976).

Foi realizada uma revisão bibliográfica prévia e somente foram encontrados trabalhos referentes aos aspectos morfológicos de Passiflora edulis Sims.(ABANTO \& MÜLLER, 1972). Este trabalho tem como objetivo estudar os aspectos anatômicos da raiz, caule e folha de $\underline{\mathbf{P}}$. alata, como parte de um projeto que visa descrever anatomicamente as espécies de Passiflora ocorrentes no Rio Grande do Sul.

\section{MATERIAL E MÉTODOS}

O trabalho foi desenvolvido no Departamento de Biologia da Universidade Federal de Santa Maria, RS

O material foi coletado no Campus da UFSM, no periodo de março a dezembro de 1992. Parte deste material foi fixado em álcool $70^{\circ}$ para conservação, e parte em FAA $50 \%$ por 48 horas, para ser submetido a técnica usual de inclusão em parafina (JOHANSEN, 1940), utilizandose o método de dupla coloração safranina-"fast-green" (SASS, 1951). Para confecção de lâminas permanentes foram feitos cortes transversais com auxilio do micrótomo rotativo e usou-se bálsamo sintético ENTELLAN para a montagem das mesmas. Como complemento da análise anatômica, foram feitos em material fresco, cortes paradérmicos em folhas, e cortes transversais em diferentes niveis da folha, do caule e da raiz.

$\mathrm{Na}$ maceração dos tecidos, foi usado o método de dissociação de Jeffrey (JOHANSEN, 1940), enquanto na dissociação da epiderme foi usado solução de água sanitária 
(hipoclorito de sódio) à $20 \%$ da comercial. Para conservação dos cortes feitos à mão livre, usou-se solução de glicerina à 33\% (JOHANSEN, 1940).

As fotomicrografias foram obtidas em microscópio "MEIJI" acoplado com aparelhagem fotográfica "RICON XR7".

\section{RESULTADOS E DISCUSSÃO}

\section{Anatomia da Raiz}

A análise seriada de cortes transversais realizada cerca de $1,0 \mathrm{~cm}$ da raiz, mostrou que a epiderme é unisseriada. O córtex está constituido de parênquima e endoderme.O primeiro está formado por 9-12 camadas de células arredondadas, apresentando grandes espaços intercelulares, enquanto que a endoderme está formada por uma camada de células taniniferas, delimitando perfeitamente córtex e cilindro central. Ainda no parênquima cortical, observou-se idioblastos, com conteúdo semelhante as células taniniferas presentes na endoderme. A região do periciclo é formada por 2-4 camadas de células parenquimáticas (figura 1). Em algumas raizes estudadas, observou-se nesta região, a presença de fibras esclerenquimáticas. METCALFE (1965) citou esta característica para o caule de algumas espécies de Passiflora. A estrutura da raiz é tetrarca, com floema intercalado nas arestas do protoxilema.

Cortes realizados na região de ramificação, mostraram que o xilema primário se mantém no centro do órgão, enquanto o câmbio vascular apresenta-se muito desenvolvido, havendo a formação de quatro regiões de xilema secundário, separados por raios medulares multisseriados (figura 2). Estas características estão de acordo com as mencionadas por ABANTO \& MÜLLER (1972) para $\underline{\text { P. edulis. }}$

O súber, na periderme, é constituído de células quadrangulares com conteúdo de tonalidade âmbar.

\footnotetext{
Anatomia do Caule

Cortes transversais, realizados em diversas regiões do caule, mostraram que este órgão é revestido por uma epiderme unisseriada com células tabulares, de paredes externas bastante cutinizadas e ausência total de tricomas; no córtex ,há um colênquima subepidérmico intercalado com parênquima clorofilico, seguidos por células parenquimáticas maiores, geralmente com grãos de amido. Nesta região, observou-se ainda, cordões de fibras.
} 
A estrutura caulinar é eustélica, com os feixes vasculares colaterais (figura 3). Externamente a estes, encontra-se cordões de fibras externos ao floema primário, concordando com o mencionado por METCALFE (1965).

Observando o corte com aumento de $400 x$, notou-se a predominância da região medular em relação ao córtex. A medula apresenta-se preenchida por um parênquima formado por células grandes, arredondadas e com poucos espaços intercelulares.

Caules dissociados mostram a ocorrência de elementos de vaso com tamanho, forma e calibre variados, mas sempre com placa de perfuração simples. Ocorrem fibras septadas com conteúdo celular.

As características citadas acima, coincidem com o que foi descrito por METCALFE (1965) para algumas espécies de Passiflora

\section{Anatomia da Folha}

A folha apresenta estrutura dorsiventral tipica. Cortes transversais mostraram que a epiderme é unisseriada em ambas as faces, sendo as células da epiderme adaxial maiores do que as células da epiderme abaxial. A cuticula é fina, com ausência total de tricomas (figura 4). Os estômatos apresentam-se no mesmo nivel das demais células epidérmicas.

Em cortes paradérmicos (figura 5), observou-se estômatos somente na epiderme abaxial, sendo do tipo anomocitico (ESAÚ, 1974).

O mesofilo está constituido por uma camada de parênquima paliçádico, com células justapostas. $O$ parênquima lacunoso é formado por 4-5 camadas de células de forma irregular, com grandes espaços intercelulares, sendo estes menores e pouco numerosos quando a folha é jovem (figura 4)

O feixe vascular que forma a nervura principal é colateral (figura 6), apresentando uma estrutura glandular junto à epiderme adaxial . Provavelmente esta estrutura seja semelhante a mencionada por ABANTO \& MÜLLER (1972), como uma saliência pronunciada abaixo da epiderme junto à nervura principal de $\underline{\underline{P}}$ edulis.

\section{Pecíolo}

Cortes realizados na região mediana do peciolo, mostram que este apresenta uma forma subcilindrica e acanalada superiormente. A epiderme é unisseriada, sendo a camada 
subepidérmica formada por células preenchidas por conteúdo avermelhado, cuja composição não foi identificada (figura 7).

Abaixo da epiderme, observou-se 3-5 camadas de células colenquimáticas seguidas de um parênquima formado por células maiores do que aquelas, onde aparece 7-9 feixes vasculares periféricos, um feixe central e dois feixes menores nas alas do pecíolo, coincidindo com o descrito por METCALFE (1965) para $\underline{\underline{P}}$. racemosa Brot.. Neste parênquima, foram observadas muitas drusas.

Externamente, o peciolo apresenta 1 ou 2 pares de glândulas (nectários). A figura 8 mostra a estrutura de um nectário extra-floral em corte longitudinal.

\section{CONCLUSÃO}

A execução deste trabalho oportunizou o conhecimento anatômico dos órgãos vegetativos de $\underline{\mathbf{P}}$ alata. Como este faz parte de um projeto que visa descrever anatomicamente as espécies de Passiflora ocorrentes no Rio Grande do Sul, até o momento, conclui-se que Passiflora alata apresenta a estrutura anatômica semelhante à de $\underline{\mathbf{P}}$. edulis, uma das espécies selecionadas do projeto, cuja anatomia já conhecida, e também, a qual, no Rio Grande do Sul, é cultivada e apresenta a mesma importância econômica.

\section{REFERÊNCIAS BIBLIOGRÁFICAS}

ABANTO \& MÜLLER; MÜLLER, L. Algunos aspectos morfológicos del maracujá, Passiflora edulis. Turrialba, v. 22, n.3, 1972. p. 268-274.

COIMBRA, R.; DINIS, E. Notas de fitoterapia. Rio de Janeiro: Lab. Silva Araújo, 1942.

ESAÚ, K. Anatomia das plantas com sementes. São Paulo: Edgar Blücher, 1976.

JOHANSEN, D. A. Plant microtechnique. New York: McGraw Hill, 1940.

METCALFE, C. R.; CHALK, L. Anatomy of the dicotyledons. Oxford: Clarendon Press, 1965.

RIZZINI, C.T.; MORS, W. B. Botânica econômica brasileira. São Paulo: EPU, 1976.

SACCO, J. C. Flora ilustrada catarinense - Passifloráceas. Itajaí: Herbário Barbosa Rodrigues, 1980.

SASS, J. E. Botanical microtechnique. 2 ed. Iowa: Iowa State College, 1951. 


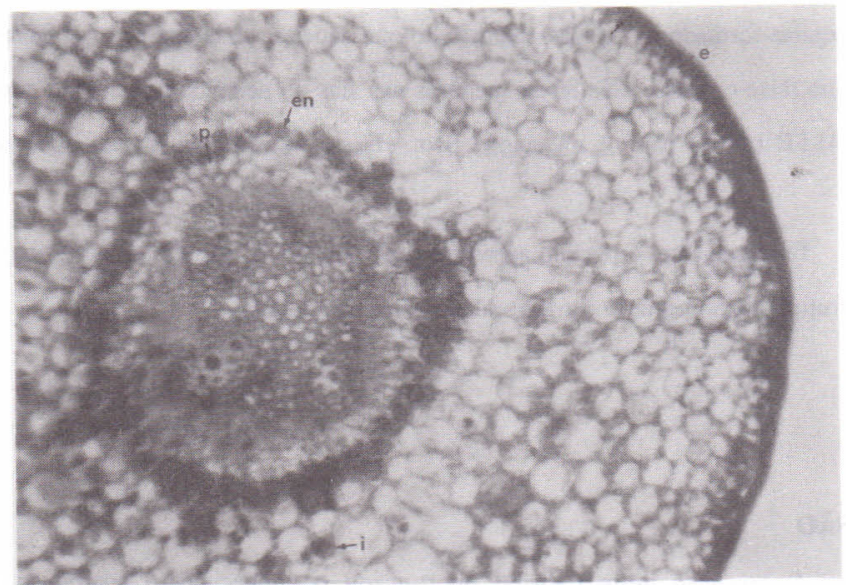

Figura 1. Corte transversal da raiz de $\underline{\mathbf{P}}$. alata, em crescimento primário. Epiderme (e), endoderme $(e n)$, periciclo $(p)$, idioblastos (i) $(400 x)$.

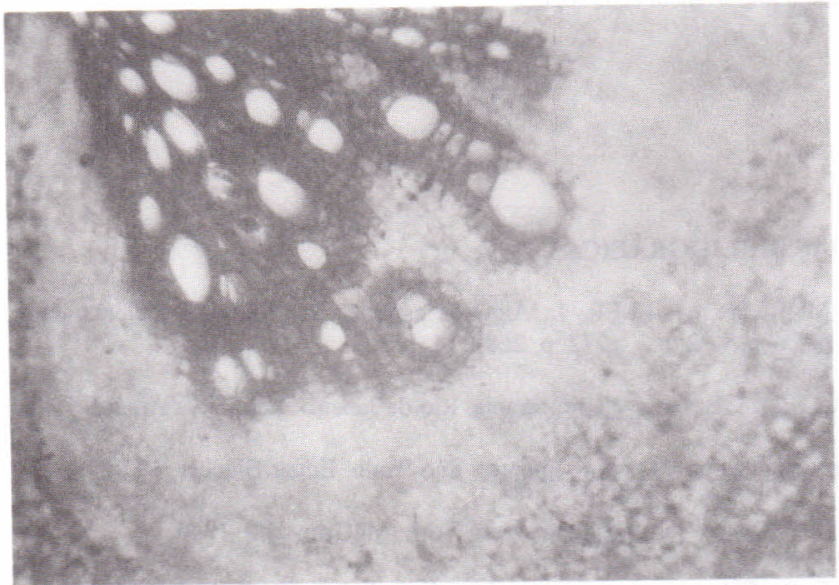

Figura 2. Corte transversal da raiz de $\underline{P}$ alata, em início de crescimento secundário (400x). 


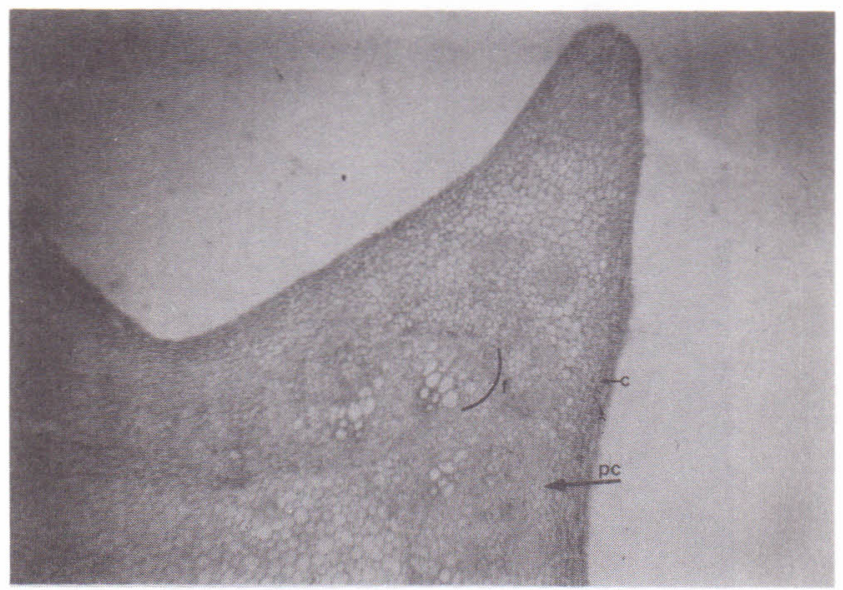

Figura 3. Corte transversal do caule de $\underline{\mathbf{P}}$ alata, em crescimento primário. Feixe vascular (f), colênquima (c), parênquima clorofilico (pc) $(400 x)$.

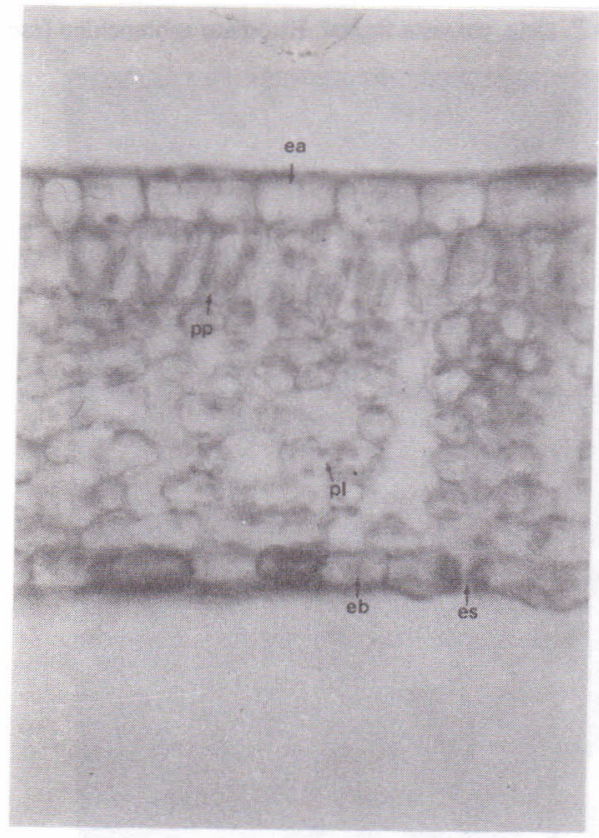

Figura 4. Corte transversal da lâmina foliar de $\underline{\mathbf{P}}$ alata. Epiderme adaxial (ea),epiderme abaxial (eb), parênquima paliçádico (pp), parênquima lacunoso (pl), estômato (es) $(400 \mathrm{x})$. 


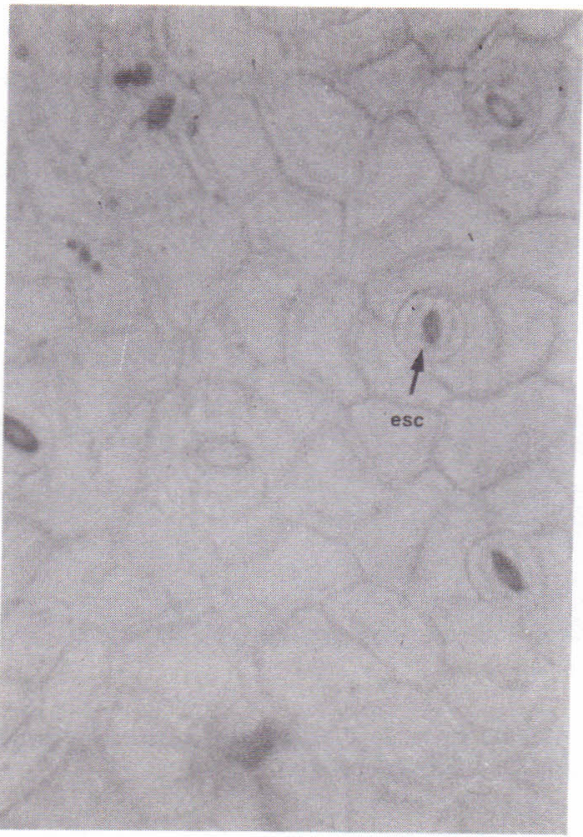

Figura 5. Lâmina foliar de $\underline{\mathbf{P}}$ alata, em vista frontal. Estômato anomocítico (esc) (400x).

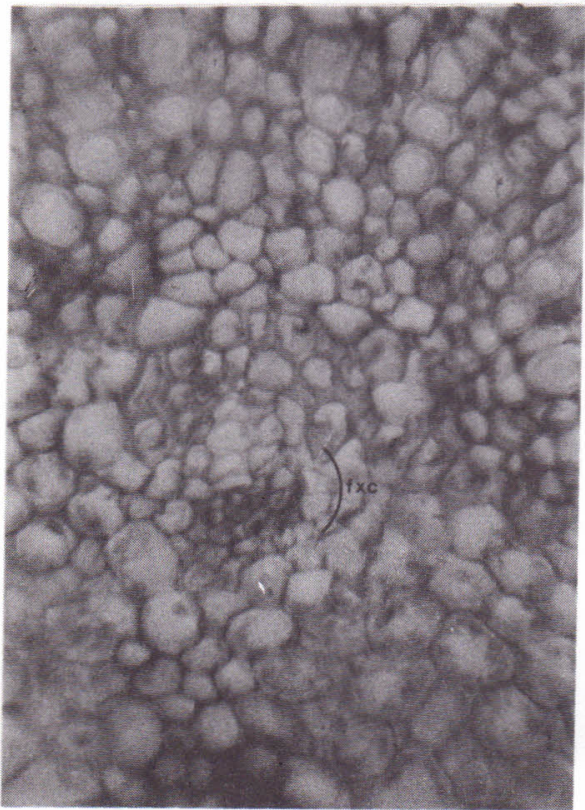

Figura 6. Corte transversal da lâmina foliar de $\underline{\mathbf{P}}$. alata, na região da nervura principal. Feixe vascular colateral $(\mathrm{fxc})(400 \mathrm{x})$. 


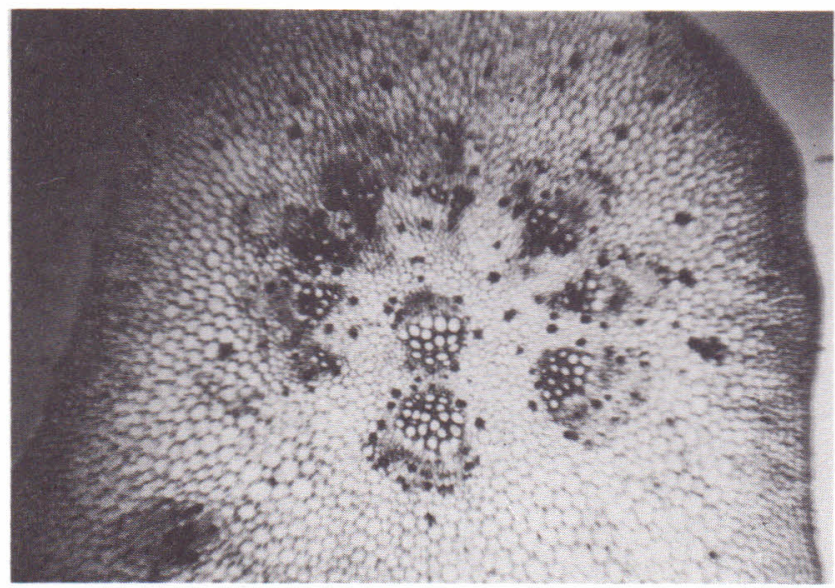

Figura 7. Corte transversal do peciolo de $\underline{\mathbf{P}}$ alata $(400 \mathrm{x})$.

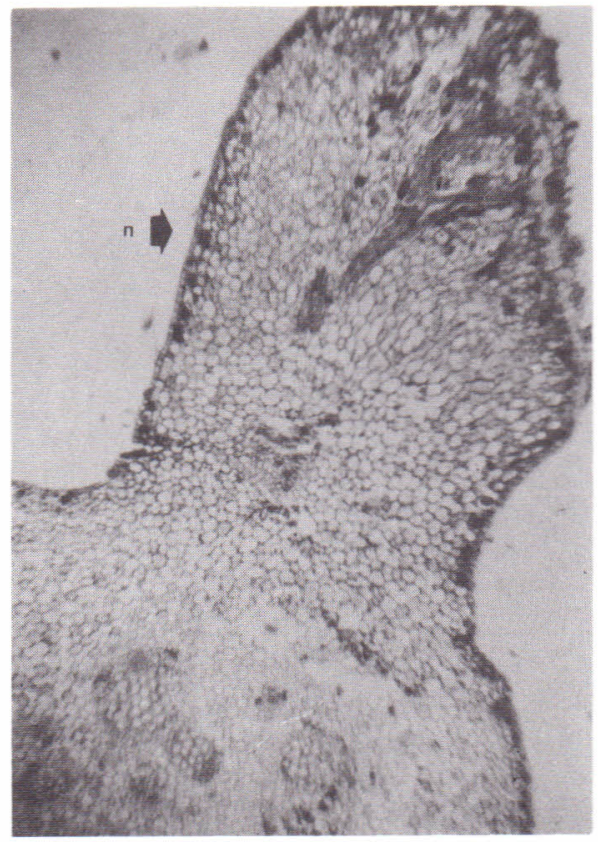

Figura 8. Corte transversal do peciolo de $\underline{\mathbf{P}}$ alata, na região do nectário. Nectário em corte longitudinal (n) (400x) 
